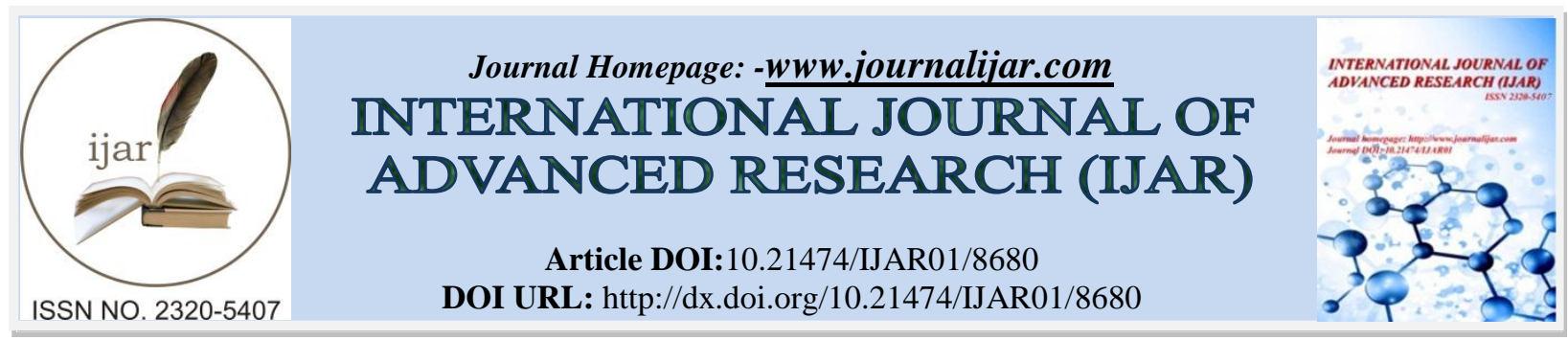

RESEARCH ARTICLE

\title{
ANALYSIS OF COMPLICATIONS AND ABNORMAL CONDITIONS ASSOCIATED WITH THALASSEMIA MAJOR: A QUESTIONNAIRE BASED STUDY.
}

\section{Sana Eijaz ${ }^{1}$, Sadaf Shaikh ${ }^{2}$, Iqra Waqar ${ }^{3}$ and Amna Mariyam ${ }^{4}$.}

1. Assistant Professor, Ph.D. (Molecular Medicine), Department of Microbiology, University of Karachi, Karachi, Pakistan.

2. M.Sc student, Department of Microbiology, University of Karachi, Karachi, Pakistan.

\section{Manuscript Info}

\section{Manuscript History}

Received: 13 January 2019

Final Accepted: 15 February 2019

Published: March 2019

Key words:-

Thalassemia, complications, hemoglobin, blood transfusion, awareness, cousin marriages.

\begin{abstract}
In this survey, we examined the associated complications and conditions of the patients suffering with Beta Thalassemia major. We focused on major factors which can be helpful to critically understand, diagnose and treat this hematological disorder. This study was conducted at Al-Mustafa Medical Centre, Karachi, Pakistan, from September 2017 to March 2018. A questionnaire was prepared to collect the data and questions were directly asked either from the patient and/or their attendants. Majority of the patients were the part of our survey range between the ages of 1 to 20 years. All the age groups showed the associated complications and different abnormal body conditions. From the total 152 patients, 81 were males and 71 were females. In all patients; fatigue, weakness and pale yellow skin was observed only when blood level becomes low. Among all the patients, $48(31.57 \%)$ patients showed slow physical growth, 38 (25\%) patients complained of abdominal swelling, 68 (44.73\%) patients were excreting dark urine, $50(32.89 \%)$ patients had enlarged spleen and 4 patients have experienced splenectomy. In case of treatment options, $128(84.21 \%)$ patients were on blood transfusions while the rest 24 (15.7\%) were taking hydroxyurea tablets. In addition to this, it was also noticed that the parents of $72.36 \%$ patients have cousin marriages. Male and female both genders equally experience thalassemia and its related complications. Lack of awareness and knowledge was found in the families which were the part of our study. As this disease is becoming common and prevailing worldwide, government should take serious measures on conducting awareness sessions and educating people that how cousin marriages may be the leading cause of this disease, making the life of their own child difficult.
\end{abstract}

Copy Right, IJAR, 2019,. All rights reserved.

\section{Introduction:-}

In 1920, Thalassemia first reported by a Detroit physian and also known as "Cooley's Anemia" and "Mediterranean Anemia". He conducted a study on two young italian children diagnosed with the disease of blood and were showing the decrease level of red blood cells, slow growth, abdominal swelling and were died at early age. It is a

Corresponding Author:-Sana Eijaz. 
genetically inherited hematological disorder in which body makes an abnormal form of hemoglobin and there is the destruction of high number of red blood cells which leads to anemia (Galanello and Origa, 2010; Winichakoon et al., 2015). In Pakistan, an approximate carrier rate is 5-8 \% with 5000 children being diagnosed each year with thalassemia major (Hashim et al., 2018). The treatment options associated with thalassemia are the frequent blood transfusion, bone marrow transplantion, iron chelation therapy and medication. These treatments permit the normal growth and development and increase the life span (Galanello and Origa, 2010). However, due to the repeated transfusions, there is a risk of AIDS, hepatitis B, hepatitis C, secondary bacterial and parasitic infections as well as allergic reactions (Hashim et al., 2018). In order to avoid these problems, proper screening of donors blood must be performed (Borhany et al., 2011).

Various abnormal conditions are strongly associated with beta thalassaemia including fatigue, weakness, pale yellow skin, slow growth, dark urine, spleen enlargement, liver and heart problems, abdominal swelling and bone deformities. The initial symptoms appear in the first two years of life are severe anemia and slow growth rate of child. As the thalassemic patients are on the regular blood transfusions, iron chelation therapy is given to reduce iron overload. Chelating agents bind to iron and passes out in urine making the urine dark coloured. The spleen enlargement is due to the red blood cells which trapped in it in an abnormal shape. This makes it overloaded and causes irregular growth in size and leads to abdominal swelling. Splenectomy can bring down the need of transfusion as it results in extended life of red blood cells. Another prominent aspect linked with beta thalassemia major is bone deformities which arise due to the expansion of bone marrow. This causes bones to widen result in abnormal structure of bones particularly of the face and skull (Akhtar et al., 2016).

Developing countries has been found to be at the high risk of getting transfusion transmitted infections (TTI), especially the beta thalassemia major patients are markedly at the greatest risk to get infected due to the frequent transfusions. It has been reported that Pakistan has high number of thalassemic patients with beta thalassemia major and the possible reasons behind this elevated prevalence are the social and cultural systems prevailing in the country (Kiani et al., 2016). A study conducted on donors' blood in Pakistan and revealed the presence of different pathogens i.e. hepatitis $\mathrm{B} ; 1.46 \%$ to $2.99 \%$, hepatitis $\mathrm{C} ; 3.01 \%$ to $4.99 \%$ and HIV; $0 \%$ to $0.06 \%$. Most of the time, proper screening is not performed due to the high-priced tests therefore patients are subjected to inadequate screened blood (Borhany et al., 2011).

The aim of this survey was to find out the associated-abnormal conditions and complications in beta thalassemic patients so that clinicians and researchers could specifically focus on the reduction of these complications and the associated-abnormal conditions. This study also focused on frequently used treatment options and the extent of awareness about this hematological disorder in these patients.

\section{Materials and Methods:-}

The cross-sectional study was conducted from September 2017 to March 2018 in collaboration with Al-Mustafa Medical centre located in Karachi, Pakistan. This study comprised on patients diagnosed with beta thalassemia major who visited to the Thalassemic unit of the Al-Mustafa Medical Centre. In the survey, those patients were included who followed up, could communicate and volunteered to participate in the study. Those, with existence of physical diseases at a level that hinders the completion of the questionnaires and those who were undergoing treatment due to a psychiatric disease were excluded. The study protocol and the questionnaire were approved by the Head of the Department of Microbiology, University of Karachi and the Head of the Thalassemic unit of the AlMustafa Medical Centre, Karachi. The written informed consent was obtained from all the participants.

A questionnaire was prepared in English as well as in Urdu in order to conduct the survey comprises of different questions. In total, 152 beta thalassemic patients were randomly selected and interrogated. The questionnaire begins with the Socio-Demographic data (age and gender) followed by asking the blood groups, type of thalassemia in patients either beta thalassemia major or alpha thalassemia major, various complications including abdominal swelling, enlarged spleen, splenectomy, heart and liver problems, emergence of any new disease etc. Additionally, the questionnaire also included the associated abnormal signs and symptoms i.e. fatigue, weakness, pale yellow skin, slow growth rate and bone deformities. Other information asked was about the age at which the disorder was diagnosed, how the particular patient is being treated, how many times a patient visit the thalassemic unit for blood transfusion and the secondary infections if any. All these questions were directly asked either from the patient or the attendant. Apart from these questions, family history and the quality of life of a patient was also the focus point of our survey (Riaz et al., 2011; Shah et al., 2017). 


\section{Results:-}

A total of 152 beta thalassemic patients were the part of our study with an age range from 11 month to 26 years. First of all, age, gender and blood groups of the patients were asked. 81 were males and 71 were females. Of these, 52 patients had $\mathrm{O}^{+\mathrm{ve}}$ blood group, 19 had $\mathrm{AB}^{+\mathrm{ve}}, 30 \mathrm{~A}^{+\mathrm{ve}}, 46 \mathrm{~B}^{+\mathrm{ve}}, 2$ were found to be $\mathrm{O}^{-\mathrm{ve}}, 1$ patient was $\mathrm{B}^{-\mathrm{ve}}$ and 2 patients were $\mathrm{AB}^{-\mathrm{ve}}$. It was observed that the patient show few specific signs i.e. fatigue, weakness and pale yellow skin (Table I) when he / she in need of blood transfusion and having low blood level.

Slow growth was found in only 48 patients while the remaining 104 patients were having normal growth as said by their parents (Table II \& III). 50 patients complained that they had enlarged spleen and 4 patients have experienced splenetomy (Table IV \& V). The rest of the patients were having the normal spleen (Table VI). To the question about abdominal swelling, 38 patients replied they had swelling in their lower region while the rest of the patients had no such case (Table VII). Heart and liver problems are also associated with beta thalassemic patients but in our survey, none of the patients came across with this issue. It was also found out that out of 152, 68 patients were suffering from the problem of dark urine but the remaining 84 patients overcome this problem with the plenty of water intake (Table VIII \& IX). Due to the frequent transfusions, thalassemic patients are always at the risk of blood-borne and secondary infections. However, after analyzing all the questionnaires it was seen that not a single patient suffered from any infectious disease.

The two major key factors i.e. diagnosis and treatment, were also the main points of our survey. While having the discussion with the patient's parents, it was recorded that the children were diagnosed in their early months of life and had fever for long period of time. In order to confirm the occurrence of this disorder, complete blood count (CBC) and iron test were performed. These tests depicted a drastic decline in the red blood cells count and the iron level and, the disorder was further confirmed by Hemoglobin electrophoresis and DNA testing.

Our questionnaire also included the questions about the particular treatment procedures and it was found that the patients go through the blood transfusions and the use of hydraoxyurea tablets. These two treatment options were recommended as per the conditions of the patient and after DNA testing. It was noticed that 128 patients were on blood transfusions and 24 patients were on hydraoxyurea tablets (Table X \& XI). The transfusion procedures were scheduled either once or twice a month, based on patient's hemoglobin level. When a patient comes for transfusion, their hemoglobin was firstly checked. If the level found below 7.0, the blood transfusion done otherwise, the patient advised to go back. Out of the 152 patients, 110 patients told that their parents have cousin marriages and 42 have the outside marriages. It was told that all the patients led a normal life with no specific diet concern and they indulged in all types of activities. Some were school and college going and some were on good jobs.

\section{Discussion:-}

Thalassemia is a genetically inherited disorder in which the body has abnormal form or inadequate amount of hemoglobin (Palit et al., 2012).We opt for this blood disorder as a topic of our survey since it is becoming a common and dominant disease worldwide. It is reported that with approximately 9.8 million carriers in the total population, nearly 5000-9000 children born with beta thalassemia every year (Ansari et al., 2011). In general, the life expectancy of thalassemic patient is fifteen to twenty years and blood transfusion is the most widely used treatment option.

The aim of our questionnaire based study was to analyze the associated conditions and complications, diagnosis and treatment options and, the level of awareness regarding this disorder. Three of the most common factors seen in all the patients i.e. fatigue, weakness and pale yellow skin which are strongly correlated with the low level of blood. Since in these patients body is unable to make sufficient amount of hemoglobin that is why the red blood cells do not function properly and they remain in the body for shorter period of time. The most important function of red blood cells is to carry oxygen to all the tissues. As there is abnormal and low level of hemoglobin, the red blood cells do not deliver appropriate amount of oxygen to the tissues and this makes the person feel tired and weak. When there is low level of blood, skin colour changes to pale yellow (Palit et al., 2012).

The function of spleen is to destroy old and damaged red blood cells and as a result iron and globin release. In case of thalassemia, the life span of red blood cells is about 30-60 days and iron often stays inside the spleen rather being reused. Additionally, the red blood cells often get stuck due to their smaller size and irregular shape and these are 
the two factors cause splenomagaly and in our survey it was also noticed. This splenomegaly may also cause abdominal swelling (http://www.cooleysanemia.org/updates/pdf/Spleen.pdf).

Due to the frequent blood transfusions, these patients are at the risk of iron overload in the body. Excess iron accumulation causes the liver and heart problems and also affects the endocrine system. Endocrine system consists on various glands which make several essential hormones. One of the master glands is pituitary gland that secretes the growth hormone. In thalassemic patients, there is an iron overload and due to which the pituary gland does not produce the growth hormone in sufficient amount. This leads to the slow growth which also observed in $31.57 \%$ of the patients (Abdulzahra et al., 2011; Shah et al., 2010). To overcome this problem, the patients are asked to take iron chelation therapy. When iron chelators get combine to iron, dark coloured urine excreted out and $44.73 \%$ of the patients complained about this problem. The remaining patients overcome this issue by a lot of water intake.

Blood transfusion is potentially associated with the transmission of infectious agents. However, in our survey, none of the patient showed the presence of any infection. This was because of the proper screening of the transfused blood in the respective local hospital. In our survey, blood transfusion and hydroxyurea (hydra) tablets were found to be the treatment options. The purpose of hydroxyurea tablet is to increase the hemoglobin level and the patients who take these tablets, receive the blood transfusion after years. As per our observed results, 84.21\% patients were being treated through blood transfusion because these tablets are not compatible to every patient. Cousin marriages were reported as the major cause of this disease as the parents of $72.36 \%$ patients were cousins of each other.

Our survey may help the researchers and clinicians to specifically concentrate and reduce the complications and abnormal conditions associated with the thalassemic patients.

\section{Conclusion:-}

Lack of awareness and knowledge was the most striking point seen in the families belonging to the lower class. As this disease becoming common and worldwide, government should take serious measures on conducting awareness sessions and educating people that how cousin marriages can be the leading cause of this disease, making the life of their own child difficult. Testing of both male and female should be done before marriage. In order to reduce the associated transfusion problems, every hospital must have proper screening of donor's blood. Separate blood banks should be there with well-organized, cold storage facilities for storing the blood. Promoting the maximum knowledge is the only positive measure which could reduce the incidence level of this disorder.

Table I :-Age-wise distribution of Male and Female patients showing Fatigue/Weakness/Pale yellow skin

\begin{tabular}{|c|c|c|}
\hline \multicolumn{3}{|c|}{ Fatigue/weakness/pale yellow skin } \\
\hline Age & Male (81) & Female (71) \\
\hline $1-5 \mathrm{yr}$ & 25 & 31 \\
\hline $6-10 \mathrm{yr}$ & 28 & 20 \\
\hline $11-15 \mathrm{yr}$ & 18 & 14 \\
\hline $16-20 \mathrm{yr}$ & 10 & 3 \\
\hline $21-25 \mathrm{yr}$ & --- & 1 \\
\hline $26-30 \mathrm{yr}$ & --- & 1 \\
\hline 11 months & --- & 1 \\
\hline
\end{tabular}

Table II :-Age-wise distribution of Male and Female patients showing Slow growth

\begin{tabular}{|c|c|c|}
\hline & \multicolumn{2}{|c|}{ Slow growth } \\
\hline Age & Male (81) & Female (71) \\
\hline $1-5 \mathrm{yr}$ & 2 & 4 \\
\hline $6-10 \mathrm{yr}$ & 6 & 13 \\
\hline $11-15 \mathrm{yr}$ & 10 & 7 \\
\hline $16-20 \mathrm{yr}$ & 3 & 2 \\
\hline $21-25 \mathrm{yr}$ & ----- \\
\hline $26-30 \mathrm{yr}$ & --- & 1 \\
\hline 11 months & --- & --- \\
\hline
\end{tabular}


Table III :-Age-wise distribution of Male and Female patients showing Normal growth

\begin{tabular}{|c|c|c|}
\hline \multicolumn{2}{|c|}{ Normal growth } & Female (71) \\
\hline Age & Male (81) & 27 \\
\hline $1-5 \mathrm{yr}$ & 23 & 7 \\
\hline $6-10 \mathrm{yr}$ & 22 & 1 \\
\hline $11-15 \mathrm{yr}$ & 8 & 1 \\
\hline $16-20 \mathrm{yr}$ & 7 & --- \\
\hline $21-25 \mathrm{yr}$ & --- & 1 \\
\hline $26-30 \mathrm{yr}$ & --- & \\
\hline 11 months & --- & \\
\hline
\end{tabular}

Table IV:-Age-wise distribution of Male and Female patients showing Spleen enlargement

\begin{tabular}{|c|c|c|}
\hline \multicolumn{2}{|c|}{ Spleen Enlargement } \\
\hline Age & Male (81) & Female (71) \\
\hline $1-5 \mathrm{yr}$ & 4 & 10 \\
\hline $6-10 \mathrm{yr}$ & 11 & 7 \\
\hline $11-15 \mathrm{yr}$ & 6 & 1 \\
\hline $16-20 \mathrm{yr}$ & 4 & --- \\
\hline $21-25 \mathrm{yr}$ & --- & 1 \\
\hline $26-30 \mathrm{yr}$ & --- & -- \\
\hline
\end{tabular}

Table V:-Age-wise distribution of Male and Female patients showing Spleen removal

\begin{tabular}{|c|c|c|}
\hline \multicolumn{2}{|c|}{ Spleen removal } \\
\hline Age & Male (81) & Female (71) \\
\hline $1-5 \mathrm{yr}$ & --- & --- \\
\hline $6-10 \mathrm{yr}$ & --- & 1 \\
\hline $11-15 \mathrm{yr}$ & 2 & --- \\
\hline $16-20 \mathrm{yr}$ & 1 & --- \\
\hline $21-25 \mathrm{yr}$ & --- & --- \\
\hline $26-30 \mathrm{yr}$ & --- & -- \\
\hline 11 months & --- & \\
\hline
\end{tabular}

Table VI:-Age-wise distribution of Male and Female patients showing Normal spleen

\begin{tabular}{|c|c|c|}
\hline \multicolumn{2}{|c|}{ Normal spleen } & Female (71) \\
\hline Age & Male (81) & 25 \\
\hline $1-5 \mathrm{yr}$ & 21 & 10 \\
\hline $6-10 \mathrm{yr}$ & 17 & 6 \\
\hline $11-15 \mathrm{yr}$ & 10 & 2 \\
\hline $16-20 \mathrm{yr}$ & 5 & 1 \\
\hline $21-25 \mathrm{yr}$ & --- & -- \\
\hline $26-30 \mathrm{yr}$ & --- & 1 \\
\hline 11 months & --- & \\
\hline
\end{tabular}

Table VII:-Age-wise distribution of Male and Female patients showing Abdominal swelling

\begin{tabular}{|c|c|c|}
\hline \multicolumn{2}{|c|}{ Abdominal swelling } \\
\hline Age & Male (81) & Female (71) \\
\hline $1-5 \mathrm{yr}$ & 6 & 5 \\
\hline $6-10 \mathrm{yr}$ & 5 & 4 \\
\hline $11-15 \mathrm{yr}$ & 6 & 1 \\
\hline $16-20 \mathrm{yr}$ & 3 & --- \\
\hline $21-25 \mathrm{yr}$ & --- & 1 \\
\hline $26-30 \mathrm{yr}$ & --- & - \\
\hline 11 months & --- & \\
\hline
\end{tabular}


Table VIII :-Age-wise distribution of Male and Female patients showing Dark urine

\begin{tabular}{|c|c|c|}
\hline \multicolumn{2}{|c|}{ Dark urine } \\
\hline Age & Male (81) & Female (71) \\
\hline $1-5 \mathrm{yr}$ & 8 & 15 \\
\hline $6-10 \mathrm{yr}$ & 15 & 5 \\
\hline $11-15 \mathrm{yr}$ & 10 & --- \\
\hline $16-20 \mathrm{yr}$ & 4 & 1 \\
\hline $21-25 \mathrm{yr}$ & --- & -- \\
\hline $26-30 \mathrm{yr}$ & --- & 1 \\
\hline 11 months & --- & \\
\hline
\end{tabular}

Table IX :-Age-wise distribution of Male and Female patients showing Normal urine

\begin{tabular}{|c|c|c|}
\hline \multicolumn{2}{|c|}{ Normal urine } & Female (71) \\
\hline Age & Male (81) & 16 \\
\hline $1-5 \mathrm{yr}$ & 17 & 11 \\
\hline $6-10 \mathrm{yr}$ & 13 & 9 \\
\hline $11-15 \mathrm{yr}$ & 8 & 3 \\
\hline $16-20 \mathrm{yr}$ & 6 & --- \\
\hline $21-25 \mathrm{yr}$ & --- & 1 \\
\hline $26-30 \mathrm{yr}$ & --- & -- \\
\hline 11 months & --- & \\
\hline
\end{tabular}

Table X :-Age-wise distribution of Male and Female patients showing Blood transfusion

\begin{tabular}{|c|c|c|}
\hline \multicolumn{2}{|c|}{ Blood transfusion } \\
\hline Age & Male (81) & Female (71) \\
\hline $1-5 \mathrm{yr}$ & 20 & 25 \\
\hline $6-10 \mathrm{yr}$ & 23 & 17 \\
\hline $11-15 \mathrm{yr}$ & 17 & 3 \\
\hline $16-20 \mathrm{yr}$ & 18 & 12 \\
\hline $21-25 \mathrm{yr}$ & --- & 1 \\
\hline $26-30 \mathrm{yr}$ & --- & 1 \\
\hline 11 months & --- & \\
\hline
\end{tabular}

Table XI:-Age-wise distribution of Male and Female patients showing use of Hydra tablets

\begin{tabular}{|c|c|c|}
\hline \multicolumn{2}{|c|}{ Hydra tablet } & Female (71) \\
\hline Age & Male (81) & 6 \\
\hline $1-5 \mathrm{yr}$ & 5 & 3 \\
\hline $6-10 \mathrm{yr}$ & 5 & 2 \\
\hline $11-15 \mathrm{yr}$ & 1 & --- \\
\hline $16-20 \mathrm{yr}$ & 2 & --- \\
\hline $21-25 \mathrm{yr}$ & --- & --- \\
\hline $26-30 \mathrm{yr}$ & --- & -- \\
\hline 11 months & --- & \\
\hline
\end{tabular}




\section{References:-}

1. Akhtar, I. K., Ashraf, M., Khalid, I. U. and Hussain, M. (2016): Surgical outcome of spelenectomy in Thalassemia major in children. Pak J Med Sci., 32: 305-308.

2. Ansari, S. A., Shamsi, T. S., Ashraf, M., Bohray, M., Farzana, T., Khan, M. T., Perveen, K., Erum, S., Ansari, I., Nadeem, M., Ahmed, M. and Raza, F. (2011): Molecular epidemiology of $\beta$-thalassemia in Pakistan: Far reaching implications. Int J Mol Epidemiol Genet., 2: 403-408.

3. Abdulzahra, M. S., Al-Hakeim, H. K. and Ridha, M. M. (2011): Study of the effect of ironoverload on the function of endocrine glands in male thalassemia patients.Asian J Transfusion, 5: 127-131.

4. Borhany, M., Shamsi, T., Boota, S., Ali, H., Tahir, N., Naz, A., Naseer, I., Farzana, T., Ansari, S., Nadeem, M., Zia-ur-Rahman and Sangji, Z. (2011): Transfusion Transmitted Infections in Patients with Hemophilia of Karachi, Pakistan. Clinical and Applied Thrombosis/Hemostasis, 17: 651-655.

5. Borgna-Pignatti, C. (2010): The life of patients with thalassemia major. Haematologica, 95: 345-348.

6. Galanello, R. and Origa, R. (2010): Beta-thalassemia. Orphanet J Rare Dis., 5: 11.

7. Hashim, S., Sarwar, M., Arsalan, A., Awan, I. andNaseem, S. (2018): Frequency of carrier screening and preventive orientation among first degree relatives of Thalassaemia patients. J Pak Med Assoc., 68: 50-54.

8. Kiani, R.A., Anwar, M., Waheed, U., Asad, M. J., Abbasi, S. and Zaheer, H.A. (2016): Epidemiology of Transfusion Transmitted Infection among Patients with $\beta$-Thalassaemia Major in Pakistan. Journal of Blood Transfusion, 2016: 1-5.

9. Palit, S., Bhuiyan, R.H., Aklima, J., Emran, T.B. and Dash, R. (2012): A study of the prevalence of thalassemia and its correlation with liver function test in different age and sex group in the Chittagong district of Bangladesh. Journal of Basic and Clinical Pharmacy, 3: 352-57.

10. Riaz, H., Riaz, T., Khan, M.U., Aziz, S., Ullah, F., Rehman, A., Zafar, Q.and Kazi,A.N.(2011): Serum ferritin levels, socio-demographic factors and desferrioxamine therapy in multi-transfused thalassemia major patients at a government tertiary care hospital of Karachi, Pakistan. BMC Research Notes, 4: 287.

11. Shah, H. B. U., Atif, I., Rashid, F., Babar, M. W., Arshad, F., Qamar, W., Khan, O. A. and Qadir, M. L. (2017): Assessment of caregiver burden of patients receiving dialysis treatment in Rawalpindi. JPMA, 67: 1498-1501.

12. Shah, N., Mishra, A., Chauhan, D., Vora, C.andShah, NR. (2010): Study on effectiveness of transfusion program in thalassemia major patients receiving multiple blood transfusions at a transfusioncentre in Western India. Asian J Transfus Sci., 4: 94-98.

13. Winichakoon, P., Tantiworawit, A., Rattanathammethee, T., Hantrakool, S., Chai-Adisaksopha, C., Rattarittamrong, E., Norasetthada L, and Charoenkwan P. (2015): Prevalence and Risk Factors for Complications in Patients with Non-transfusion Dependent Alpha- and Beta-Thalassemia. Anemia, $2015:$ 1-7.

14. http://www.cooleysanemia.org/updates/pdf/Spleen.pdf 